\title{
Satellite Analysis of the Environmental Impacts of Armed-Conflict in Rakhine, Myanmar
}

Thiri Shwesin Aung ( $\nabla$ thirishwesinaung@fas.harvard.edu )

Harvard University https://orcid.org/0000-0002-9262-531X

Article

Keywords: Google Earth Engine, Conflicts, Remote Sensing, Ecosystem, Livelihood, Machine Learning

Posted Date: December 21st, 2020

DOI: https://doi.org/10.21203/rs.3.rs-112904/v1

License: (c) (i) This work is licensed under a Creative Commons Attribution 4.0 International License. Read Full License

Version of Record: A version of this preprint was published at Science of The Total Environment on August 1st, 2021. See the published version at https://doi.org/10.1016/j.scitotenv.2021.146758. 


\section{Abstract}

The impacts of armed conflict on the environment are extremely complex and difficult to investigate, given the impossibility of accessing the affected area and reliable data limitation. Very-high-resolution satellite imageries and highly reliable machine learning algorithms become very useful in studying direct and indirect impacts of war on the ecosystem, in addition to connected effects on human lives. The Rohingya conflict is described as one of the worst humanitarian crises and human-made disasters of the 21st Century. Quantification of damage due to the conflict and the suitability of human resettlement has been lacking despite the ongoing agreements to repatriate refugees and the importance of ecosystem services for the communities' survival. Here we report the investigation of environmental conditions pre-, during, and post-conflict in the conflict zone using satellite data. We implemented and experienced the Google Earth Engine (GEE) cloud-based computing platform with a widely applied algorithm, the Random Forest (RF) classifier. We found striking near-complete demolition of inhabited regions, dramatic and highly significant increase in burning areas, and substantial deforestation. We discuss the reasons behind such findings from the Rakhine case and debate some general conservation lessons applicable to other countries undergoing post-conflict transitions.

\section{Introduction}

All over the world, the environment is being affected by anthropogenic activities. From the disruption of the Earth's climate system, ocean filling up with plastic, pollution, and forest degradation to damaging the entire ecosystem, human actions have changed the make-up of Earth's surface. While these changes are easier to detect in a politically stable context, it is notoriously challenging to assess how the environment is affected in areas faced by armed conflict, either directly by the conflict or indirectly through the socio-economic and political conditions that conflicts create. The impacts of violent conflict on human are generally well-understood and extensively documented (Cheung et al. 2020; Clodfelter 2002; Gorsevski et al. 2012; Joksimovich 2000; Sidel and Levy 2008; Spyrou et al. 2019).

These effects can have adverse, long-term, and far-reaching impacts on civilians and the surrounding ecosystem (Skakun et al. 2019). Generally, the impacts of armed conflicts on the environment are deleterious due to land mines, burning, over-exploitation of resources, and mass-movement of people. These impacts can be in the form of degradation of natural resources, forest degradation, habitat destruction, increase in water pollution, and loss of biodiversity (Baral, Heinen, and Barai 2019; Daskin and Pringle 2018; Eniang, Haile, and Yihdego 2007; Hanson 2018) Another set hypothesis, however, posits that conflicts can have unintentional positive effects on the environment resulting from a decrease in human pressure on the environment and wildlife (Burgess, Miguel, and Stanton 2015; Draulans 2002; Gorsevski et al. 2012; Rustad et al. 2008).

The key constraints to assess these impacts accurately are difficulty accessing conflict-affected areas and lack of data on both conflict and environmental loss (Burgess et al. 2015; Madden and Ross 2009). The absence of a clear spatial and temporal definition of the extend of conflict exacerbates these limitations (Butsic et al. 2015). Analyzing the effects of conflict on the environment is particularly challenging in a historically opaque and mysterious country like Myanmar. In this context, data derived from very high-resolution satellite images provide accurate information for investigating the direct impacts of conflict on the physical landscapes (Stevens et al. 2011). Satellite data has been widely applied to monitor and quantify the damages that occurred during armed conflicts in conflict-affected countries around the world (Burgess et al. 2015; Butsic et al. 2015; Gorsevski et al. 2012; Hanson et al. 2009; Nackoney et al. 2014; Witmer 2008, 2015; Witmer and O'Loughlin 2009). However, there have been limited studies that investigate the environmental impacts of armed conflicts in Myanmar.

Myanmar is a resource-rich, environmentally vulnerable, and conflict-ridden country. An alarming number of armed conflicts have persisted in Myanmar's different forms and intensity since independence from British colonization in 1948 (Christophersen and Stave 2018; Jolliffe 2014). For more than five decades, life across much of Myanmar has been profoundly affected by violent conflicts, particularly in ethnic minority populated areas. In conflict-zones, repeated incidents of the use of land mines, burning, and mass displacement of people have been ongoing catastrophes for years (Kevin M Woods 2019). In these circumstances, environmental conservation and natural resource governance are often not prioritized for both the government and the community. Hence, the scale and severity of environmental degradation caused by armed conflicts remain unknown. Most of the conflict-affected areas are closed to researchers, so it is difficult to grip the real situation and nearly impossible to conduct social science fieldwork in the region.

In this study, I used very-high-resolution (VHR) satellite imageries to investigate land use and land cover changes (LULCC) and the damages caused by recent armed-conflict in the northern Rakhine state of Myanmar. From 2012-2017, the armed forces and national police launched "area clearance operation" against the Rohingya minority in Rakhine state (Selth 2018). The Military's brutal campaign of murder, rape, and other atrocities forced more than 740,000 Rohingya to flee to Bangladesh. The vast majority of Rohingyas refugees experienced and witnessed extreme violence and their homes' destruction during the conflict. (HRW 2017)'s satellite imagery analysis showed massive destruction of villages, providing evidence for widespread arson, killing, and looting. In 2019, Gambia applied to the International Court of Justice (ICJ), alleging that Rohingyas' brutal treatment violated various provisions of the Genocide Convention. Despite the government's presidential directives for preventing crime against ethnic minorities, the fighting between the ethnic Arakan Army (AA) and Myanmar Military continues to escalate in 2019, killing hundreds of ethnic Rakhine and Rohingyas and displacing as many as 160,000 civilians. As displacement continue to rise, and access remains extremely limited for international actors and researchers. 
Time-series of satellite imagery are useful for monitoring the ground's situation over a long period to record changes resulting from conflicts (Machlis and Hanson 2011; Weir, McQuillan, and Francis 2019). I use satellite images from 2012, 2017 and 2019, to quantify the environmental degradation and livelihood destruction between pre-conflict and during the conflict in Maungdaw and Buthidaung - situated in the northern tip of Rakhine state, the epicenter of the conflict. Some of the most visible impacts of armed conflicts are the imprints left on the landscape. Remotely sensed very-highresolution (VHR) satellite data could be very useful in detecting environmental changes and depicting destroyed communities' livelihood in extremely sensitive conflict-zone. This research is motivated by the fact that the environment continues to be the silent victim of armed conflicts, and conflictinduced environmental degradation causes significant harm to the communities that depend on their livelihoods on the ecosystem services. The paper addressed six critical questions: (1) What is the intensity and pattern of environmental degradation in this conflict zone? (2) What is the magnitude of human life and livelihood destruction? (3) How many forests have been lost during the study period? (4) Are there any post-conflict afforestation, and what is the pattern of afforestation in the study area? (5) Is the place suitable for human resettlement at this current state? Finally, (6) What is the reliability of satellite data and machine learning in assessing complex conflict zones.

\section{Study Region}

The study area is located in the northern part of Myanmar's Rakhine State in Myanmar's westernmost part. It is located approximately between latitudes $17^{\circ} 30^{\prime}$ north and $21^{\circ} 30^{\prime}$ north and longitudes $92^{\circ} 10^{\prime}$ east and $94^{\circ} 50^{\prime}$ east. The total area of the state is $36,769 \mathrm{Km}^{2}$. Rakhine is one of the deforestation hotspots and has the second-highest forest loss in Myanmar. Rakhine region lost 109,024 ha of intact forests in between $2002-2014$. Rakhine also lost a significant area of mangrove forests with the highest annual loss rate in Myanmar (De Alban et al. 2020; Richards and Friess 2016). Consequently, the Rakhine state became the country's most vulnerable state to natural disasters (Kissinger et al. 2017). The contributing factors to land cover change or deforestation in Rakhine state are currently unknown and not well represented in the current literature, albeit having alarming levels of conflicts and displacements (Lim et al. 2017).

The Rohingya conflict is characterized by sectarian violence between the Rohingyas and ethnic Rakhine communities and a military crackdown on Rohingyas by the security forces (International Crisis Group 2019). There are also ongoing clashes between the Myanmar military and the ethnic Rakhine Arakan Army (HRW 2020). The satellite images of the study site cover 28,590.734 ha of conflict-affected areas in Maungdaw and Buthidaung townships. The study area was chosen based on the severity of conflict impacts and the high-resolution satellite data availability. The conflictaffected areas were identified based on Human Rights Watch's damage analysis reports (HRW 2017). HRW released the location maps of conflict extent and damage zones in Maungdaw and Buthidaung regions using high-resolution satellite images. Our satellite data covers most of the damage zones identified by HRW. The total study site's extent is 2,326.5615 km at the top, 2,299.757 km at the bottom, $415.431 \mathrm{~km}$ to the left, and $440.001 \mathrm{~km}$ to the right. Geographically, the area examined in this study extends from $19^{\circ} 49^{\prime} 41.63^{\prime \prime} \mathrm{N}$ (elevation $64 \mathrm{~m}$ ) to $19^{\circ} 52^{\prime} 26.77^{\prime \prime} \mathrm{N}$ (elevation $198 \mathrm{~m}$ ) latitude and $94^{\circ} 03^{\prime} 20.57^{\prime \prime} \mathrm{E}$ (elevation $333 \mathrm{~m}$ ) to $94^{\circ} 06^{\prime} 42.03^{\prime \prime} \mathrm{E}$ (elevation $133 \mathrm{~m}$ ) longitude. The region supports tropical rain forests, tropical mixed evergreen and deciduous forests, coastal mangrove swamps, and inland swamp forests (Davis 1965). The region is disaster-prone and has very low food security due to low agricultural productivity.

\section{Data And Image Processing}

Mapping with complex machine learning classifiers requires many representative datasets to train and validate the models (Nomura and Mitchard 2018). Figure 2 below depicts the workflow for the classification of satellite images and producing the maps. The representative training samples can be usually collected from the field to obtain geofield photos or high-resolution images (Nomura et al. 2019). In our case, conducting field visits to conflict zones was impossible due to ongoing conflicts and travel restrictions. In the absence of ground-truth data, I derived an extensive training dataset from expert interpretation from a set of VHRI Pléiades satellite data. As our classification images are VHRI, this method offers better accuracy than using Google Earth Pro for collecting training and validation data. Based on experts' regional knowledge of LULCC in the study area, I manually delineate reference data through visual interpretation, producing datasets for each study period.

I generated a total of 2,000-3,682 polygons for each respective year distributed throughout the study area to cover the entire satellite image and carefully digitized for training and validation data set. Land cover classification of the study area was primarily determined based on the existing land cover analysis and classification maps of Rakhine state developed by the United Nations Operational Satellite Applications Programme (UNOSTAT) in 2015 (OCHA 2015). The maps provide land cover classification over Rakhine state derived from Landsat 8 multi-spectral imagery acquired between January to February 2015 at 30m pixel resolution. The classification is divided into five main classes: Forest, Mangrove, Cropland (Paddy Field), Barren Soil, and vegetation. For this study, using VHRI data, I classified a total of eight categories: Forest, Barren, Development, Planted/Cultivated, Scrubland, Water, Wetland, and Burned Area. These training samples and reference data were later used as input variables for the Random Forest model's calibration. At the first step of classification, I created a binary column in the training dataset to split polygons into train (50\%) and test (50\%) using R-studio programming software.

To quantify Land-Use-Land-Cover-Change (LULCC) associated with the armed-conflict, primary data from the existing time series from the commercial VHRI orthorectified satellite images, Pléiades -1A Satellite Sensor, were collected (AIRBUS 2020). Pléiades 1A was the first high-resolution satellite in the Airbus Defense and Space constellation. Data captured very close dates for three years in the same study area. To compare pre-conflict, conflict and post-conflict periods, images from three acquisition dates ( $\mathrm{t} 0=2012$ November $11, \mathrm{t}-1=2017$ November 28 , $\mathrm{t}-2=2019$ November 26 ) with a spatial resolution of $0.5 \mathrm{~m}$ (multi-spectral bands) were used for our main study area in Maungdaw and Buthidaung townships. These images were mainly

Page 3/17 
used to track and classify land cover changes in the conflict zones, using the RF classification method. Pléiades -1A images are multi-spectral with four bands (blue: 430 - 550 nm, green: 500 - 620 nm, red: 590 - 710 nm, near-IR: 740 - 940 nm). The (pre-, during, and post-conflict) dates were chosen based on conflict peak times and cloud-free images for the study areas. Due to the monsoon climate patterns throughout Myanmar, it is challenging to obtain cloud-free satellite imagery. There are also no Synthetic Aperture Radar (SAR) covering the study period in our study region. All the images were pre-processed and mosaicked in ArcGIS Pro.

Next, I used Google Earth Engine (GEE), a cloud-based computing platform, to perform a machine learning classification algorithm. GEE is a cloudbased platform for planetary-scale geospatial analysis that enables Google's massive computational capacities to unravel the most significant problems concerning the land cover mapping of large geographical areas and big data (Gorelick et al. 2017; Noi Phan, Kuch, and Lehnert 2020). Due to its cloud computing power, data processing works, and the memory capacity of the user's computer is not a limiting factor when working with big data and imagery. Another big advantage of GEE is the consolidated library of low to moderate resolution global satellite data to supplement key VHRI data(Sidhu, Pebesma, and Câmara 2018). GEE is an efficient platform to execute complex workflows of satellite data processing required for largescale applications such as LULCC monitoring(Shelestov et al. 2017). Figure 2 below summarizes the workflow of our study using GEE, R studio, and ArcGIS Pro. I first uploaded the main satellite data and training data in Google Cloud storage and ingested into GEE asset using Python application programming interface (API). Subsequently, I extracted training and testing data in GEE to update training parameters and testing data size, naming the datasets and matching bands. I then added new bands for additional exploratory variables to include the digital elevation model (DEM), slope, and vegetation indices. I obtained Sentinel-2 images from the nearest date of the original images from the GEE archive and calculated Normalized Difference Vegetation Index (NDVI) using following formula:

$$
N D V I=\frac{\text { NIR-Red }}{\text { NIR+Red }}
$$

I first employed two supervised machine learning models Random Forest (RF) and Support Vector Machine (SVM). As the Random Forest RF model performed better than SVM, RF was chosen as our classification model after the classification. The highest overall accuracy obtained with SVM model was $46 \%$. RF is a robust model particularly appropriate for LULCC classification as it can effectively process a large number of predictor variables and complex datasets (Bricher et al. 2013; Cutler et al. 2007). The RF model outperformed other traditional parametric based image analyses because of its capacity to conform missing values and complex variables and obtain high overall classification accuracy (Belgiu and Dra 2016; Sesnie et al. 2010).

RF creates an ensemble of trees, each providing a "vote" to select the best classification approach. The majority of votes from the assemblages of the tree created in RF determine the class assignment of the pixel, and the results of the large quality of trees are aggregated internally (Berhane et al. 2018). Before classification, I conducted RF hyperparameter tuning to update bands and select the best hyperparameter values. As it is necessary to have the specification of several parameters to execute the RF model, each RF tree was established by training each tree in the forest (ntree) with the number of input predictor-variables (mtry), randomly chosen at each split from the training dataset (Aung, Fischer, and Buchanan 2020). In the last section of RF classification in GEE, I set hyperparameters values after hyperparameter tuning, trained the classifier, and exported classified raster images and accuracy assessment results to the google drive folder.

Comprehensive geospatial information, such as the conflict zones' geographical location, road network, other physical features, affected villages, and the geographic boundaries of villages and townships were derived from the Union Enterprise for Humanitarian Assistance, Resettlement and Development in Rakhine (UEHRD), the databanks of the Humanitarian Data Exchange and Myanmar Information Management Unit's GIS resources.

In addition to the accuracy assessment estimated from RF classification in GEE during the bootstrapping process (Belgiu and Dra 2016), based on the best practices recommended by (Olofsson et al. 2014), I adopted a stratified random sampling design. Accuracy assessment calculates the accuracy of maps, quantifies each class area, and evaluates the uncertainty of classifications of the area (Mellor et al. 2013; Sharma, Hara, and Hirayama 2017). The required sample size was calculated using the following formula:

$n=\frac{\left(\sum W_{i} s_{i}\right)^{2}}{[s(\hat{o})]^{2}+\left(\frac{1}{N}\right) \Sigma W_{i} s_{i}^{2}} \approx\left(\frac{\sum W_{i} s_{i}}{s(\hat{o})}\right)^{2}$

Where $n=$ number of units, $S(\hat{O})$ is the standard error of the estimated overall accuracy, Wi is

the mapped proportion of the area of class $i$ and $\mathrm{S}_{\mathrm{i}}$ is the standard deviation of $i$.

$\mathrm{S}_{\mathrm{i}}=\sqrt{U_{i}\left(1-U_{i}\right)}$ 
I defined a target standard error for the overall accuracy of 0.01 . Using the proportional approach, I allocated a sample size of $50-100$ to the smaller classes, and the rest of the samples were proportionately allocated for each change strata based on the class. The estimated variances are then computed based on the sample size allocation.

\section{Results}

The satellite imagery analysis results for the Rakhine conflict are striking (Table 1; Fig. 3 and 4). The classification maps of the study area from three points in time were investigated. This way, the environmental and human destruction in the conflict-affected zones were examined. The resulting maps are shown in Fig 4. Table 1 summarizes the calculations of the net change in the area of each land category.

The results show near-complete demolition of inhabited regions in the entire study area. At the original pre-conflict period, forests are the most extensive land cover area, followed by a residential area, water, and wetland, and planted or cultivated area. In 2012 , forest covered over $27 \%$ of total land cover. The residential area covered $21 \%$ of the study region. Overall, in Maungdaw and Buthidaung (part of the ethnic cleansing), all the land cover categories experienced dramatic and highly significant alterations in the during-conflict years (Table 1; Fig. 3). First, the results reveal shocking evidence of the massive annihilation of residential areas and human settlements. The classification shows the decrease of 5897 hectares of human settlements, which is a horrifying $99.73 \%$ damage within three years, resulting in utter destruction. This is also manifested in the before and after maps (Fig.4), where burned areas (red) drastically expanded, and the area of human settlement (pink) become almost undetectable. This widespread devastation is the result of the burning of 6940 hectares in 2017 (Table 1). These results correspond to (Human Rights Watch 2017)'s report, which has documented arson, killing, and looting during the conflict. There is a small area of burned area in 2012 . This can be partly due to the small-scale burning of villages during the first wave of violence, which started in June 2012, and in some part, due to slash-and-burn during the winter seasons.

As a result of burning, there is also a substantial decrease in planted and cultivated lands. A similar pattern was observed in the forested area, showing an overall deforestation rate of $46.59 \%$. There is also a notable decrease in the water/wetland area. This can be associated with the destruction of fishponds, shrimp farms, and other aquaculture wetland ecosystems. Another area of significant depletion is development. Based on the study area's development characteristics, I specified only roads and large infrastructures as development areas. The result can be due to the deliberate destruction of road networks to prevent victims from fleeing or returning. Hence, in the 2017 classification map, the development area (blue) is unapparent. Another appealing result is a sharp increase in barren and scrublands during the conflict. This result is also reflected in a drastic loss of planted/cultivated lands. In all, the results are elucidated in before and after maps where the vast majority of the land in 2017 is covered by burned area, barren, and scrubland (Fig. 3).

Our results from a post-conflict (2019) assessment of the study area reveal notable land cover changes (Table 1; Fig 3). There is a $97 \%$ increase in the residential area after losing more than $99 \%$ of the residential areas during the conflict. The net loss from pre-conflict periods remains over $90 \%$. Highresolution satellite images revealed several new structures and settlements in the previously destroyed areas. Fig 5 illustrates the same area during the three periods, 2012, 2017, and 2019. Map 1 shows the original status of the land before the conflict, and the second map testifies the absolute demolition of the area during the conflict, and the last map of 2019 displays the establishment of new structures, which appears to be military campsites. Some of the burned areas (2569 hectares) recovered from 2017. Based on the classification results, it can be predicted that some large area of burned residential areas has been converted to agricultural lands. The results depict notable expansion of planted/cultivated areas with 2112 hectares (+60.42\%) from 2017 to 2019 . The net loss of agriculture lands from the original state is $-49.53 \%$. The increase in the development area is also evident. The maps show some replacements of burned areas with built-up areas in 2019. The site experienced considerable reforestation during post-conflict (2017-2019) with 2399 (37.23\%) hectares of forest regrowth. However, compared with pre-conflict status, the net loss of forest is - $14.91 \%$. There is a negligible decrease in barren/scrubland and an increase in water/wetland in the post-conflict period.

The study area's NDVI maps also support the quantification of environmental degradation in these trajectories. The NDVI maps for the three periods pre-, during- and post-conflict indicate that NDVI values significantly declined between pre- and during-conflict periods and continue to decline between during- and post-conflict periods but with a much lower rate of decline in the latter interval (Fig 5). The mean NDVI values of 2012 were 0.636 , with a standard deviation (SD) of 0.196 . The mean NDVI values declined to 0.5644 (SD 0.281) in 2017. Interestingly, the loss continues to occur in 2019 as the mean NDVI value shows 0.544 (SD 0.26). The results suggest that while forest and agricultural land rebounded, vegetation's health and greenness continue to decline during the post-conflict years. The results of accuracy assessment in area propotions and sample count are presented in supplementary table 1 to 6 .

Table 1: Area (in hectares) and spatial change in land cover land use classes and overall net gain and losses between 2012, 2017 , and 2019 in the study area. 


\begin{tabular}{|c|c|c|c|c|c|c|c|c|c|c|c|c|}
\hline \multirow[t]{3}{*}{ Class Name } & \multicolumn{6}{|c|}{ Acquisition Date } & \multicolumn{6}{|c|}{ Net LULC Change } \\
\hline & \multicolumn{2}{|c|}{$2012(\mathrm{Ha})$} & \multicolumn{2}{|c|}{$2017(\mathrm{Ha})$} & \multicolumn{2}{|c|}{$2019(\mathrm{Ha})$} & \multirow{2}{*}{$\begin{array}{l}2012- \\
2017 \\
\text { Area }\end{array}$} & \multirow{2}{*}{$\begin{array}{l}2017- \\
2019 \\
\text { Area }\end{array}$} & \multirow{2}{*}{$\begin{array}{l}2012- \\
2019 \\
\text { Area }\end{array}$} & \multirow{2}{*}{$\begin{array}{l}\text { 2012-2017 } \\
\text { Percent }\end{array}$} & \multirow{2}{*}{$\begin{array}{l}2017- \\
2019 \\
\text { Percent }\end{array}$} & \multirow{2}{*}{$\begin{array}{l}\text { 2012-2019 } \\
\text { Percent }\end{array}$} \\
\hline & Area & Percent & Area & Percent & Area & Percent & & & & & & \\
\hline Residential Area & 5883 & $21 \%$ & 16 & $0 \%$ & 576 & $2 \%$ & -5867 & 560 & -5307 & $-99.73 \%$ & $97.22 \%$ & $-90.21 \%$ \\
\hline Water/Wetland & 5449 & $20 \%$ & 4965 & $19 \%$ & 4977 & $18 \%$ & -484 & 12 & -472 & $-8.88 \%$ & $0.24 \%$ & $-8.66 \%$ \\
\hline Burned Areas & 12 & $0 \%$ & 6940 & $26 \%$ & 2581 & $9 \%$ & 6928 & -4359 & 2569 & $57733.33 \%$ & $-168.89 \%$ & $21408.33 \%$ \\
\hline Planted/Cultivated & 4184 & $15 \%$ & 836 & $3 \%$ & 2112 & $8 \%$ & -3348 & 1276 & -2072 & $-80.02 \%$ & $60.42 \%$ & $-49.53 \%$ \\
\hline Barren/Scrubland & 3087 & $11 \%$ & 9543 & $36 \%$ & 9427 & $35 \%$ & 6456 & -116 & 6340 & $209.14 \%$ & $-1.23 \%$ & $205.38 \%$ \\
\hline Development & 1740 & $6 \%$ & 117 & $3 \%$ & 1179 & $4 \%$ & -1623 & 1062 & -561 & $-93.27 \%$ & $90.08 \%$ & $-32.23 \%$ \\
\hline Forest & 7572 & $27 \%$ & 4044 & $15 \%$ & 6443 & $24 \%$ & -3528 & 2399 & -1129 & $-46.59 \%$ & $37.23 \%$ & $-14.91 \%$ \\
\hline
\end{tabular}

\section{Discussion}

The use of Very-high-resolution satellite data and machine learning algorithms to investigate the impacts of armed conflict revealed catastrophic and horrendous results. Over a span of eight years (2012-2019), the seven investigated land categories underwent substantial damage in the conflict zones. Primarily, the massive area of burned land resulted in sweeping destructions of human settlement, agricultural lands, forests, developments, and wetland ecosystems. From the pre- to during-conflict period, an enormous area of land became barren or scrubland. This is driven by extensive burning and agricultural land abandonment, often common in conflict settings and highly contested regions (Witmer 2008). The deforestation inside the conflict zone is immense and accelerated with the onset of conflict. Such a massive increase in natural habitat loss, often of primary forests, and livelihood destruction have profound effects on the ecosystem and human. These forests are important natural capitals and provide essential ecosystem services for the local communities. The report from (HRW 2017)'s pinpointed the near-total destruction of villages by fire and reported that approximately $90-100 \%$ of all the villages are partially or destroyed. Our quantification and temporal comparison manifested more devastating and profound damage. The scale, scope, and timing of destruction also corroborate HRW's findings. Consistent with reports of mortality, other crimes against humanity that forced Rohingya to flee for their lives, the current study found that a wide spectrum of heavy arson attacks was committed in the region. The results also revealed that the conflict's disastrous impacts are not just on the human lives and properties, also on the environment and ecosystem. In terms of environmental harm, the magnitude and intensity of damage are the most pronounced for agricultural lands and forests. Although some recovery patterns were observed, the net decrease in both land categories remains significant in the post-conflict period. The findings of previous works on environmental impacts and recovery during the post-war period have been contradictory (Gorsevski et al. 2012; Stevens et al. 2011; Suarez et al. 2018). Although the deleterious environmental impacts of war are felt long after the conflict in most cases, some studies suggested that some forests and biodiversity rebounded after the war due to a decrease in human pressure (Kaimowitz and Fauné 2003). In our case, the result obtained from the analysis opposes the narrative that war can have positive impacts on the environment, especially during post-conflict and peace periods (Clerici et al. 2020; Reardon 2018; Stevens et al. 2011; Zúñiga-upegui et al. 2019). Although the reduction in human pressure can be beneficial for the environment, it cannot guarantee sustainable environmental security. The formation of "no-go zones" due to compromised security (Gorsevski et al. 2012) is ultimately dysfunctional and symbolic of more deep-rooted problems. The disruption of state institutions, the collapse of non-governmental organizations active in environmental initiatives, poor management of natural resources, and discriminatory land law exacerbates them. Despite being replaced by cultivations and structures to some extent, the majority of the burned area also remain unchanged. The health and quality of vegetation also has not been improved until the end of the study period. Negligible change in barren and wetland is unsurprising as repatriation and resettlement of the victims have not been implemented until 2019, and economic activities such as aquaculture businesses in wetland areas are yet to revive.

These results confirm that armed-conflicts and civil war aggravate Myanmar's already declining forest trend and degrading forest quality. Myanmar loses $0.87 \%$ of its forest cover annually (Aung et al. 2020; Leimgruber et al. 2005; Yang et al. 2019). Myanmar is also the current mangrove deforestation hotspot globally, and more than $90 \%$ of mangrove forests are located in Rakhine and Tanintharyi (De Alban et al. 2020; Richards and Friess 2016). Besides wood extraction, agricultural expansion and infrastructure development, civil war is recognized as a root cause of deforestation in Myanmar (Baskett 2016; Bhagwat et al. 2017; Connette et al. 2016; Lim et al. 2017; Prescott et al. 2017; Wang and Myint 2016). In this study, considering the intensity of forest losses occurring within the conflict zones' immediate proximity and during the conflict timeframe, all forest losses can be attributed to the conflict and its subsequent aftermath. While deforestation and afforestation co-exist, the area of deforestation is still more extensive than the afforestation. This result is different to findings from other conflict zones, such as Nicaragua's Atlantic Coast, South SudanUgandan border, and Congo (Gorsevski et al. 2012; Nackoney et al. 2014; Stevens et al. 2011). As planted/cultivated area is subsequently rebounding during the same period, the afforestation pattern might be contributed by agricultural expansion. Commercial agriculture has been used as opportunities by Military to confiscate abandoned lands and develop large-scale plantations of crops after the conflict (Lim et al. 2017; Nomura et al. 2019; Kevin M. Woods 2019). In this research, several new establishments assumed to be military campsite are shown on the maps. As of June 2019, there were no known IDP sites in Maungdaw and the humanitarian activities in the region have been village/township based (Myanmar Information 
Management Unit 2020; UNHCR 2012). The grievances resulting from land confiscation in the aftermath of conflicts ultimately undermine peacebuilding and incentivize conflict recurrence (De Alban et al. 2019; Bhagwat et al. 2017; Woods 2015). The impacts of armed conflict on humans and the environment are likely similar across other conflict-affected regions in Myanmar, although different ecosystems, conditions that led to the onset of war, and the characteristics of the conflict itself need to be considered. In this context, areas in other conflict zones should also be investigated in the future to achieve higher accuracy of modeling results. Incorporating socio-economic surveys with high-resolution imagery might also help understand the land cover fully, and land uses dynamic during the study periods.

The findings from this investigation further underscore the risk of forced repatriation of Rohingya refugees from Bangladesh. In addition to an absence of security, blatant disregard of basic human rights, and a lack of guarantee for the restoration of their housing, land, and property, the utter destruction of the ecosystem means sustainable livelihood solution is not likely upon return. Our post-conflict analysis highlighted that the Rakhine state's current situation is not yet equipped and cannot ensure the safe and voluntary return of refugees. Lack of fundamental human needs, livelihood opportunities, access to ecosystem services, among other factors, will make repatriation far from a durable solution (Naseh et al. 2018). Natural resources and environmental services underpin the livelihood of the majority of the population in the study area. If not properly managed, the combined pressure of conflict, environmental degradation, civil disorder, and the collapse of previously established livelihood systems will take a toll on both the civilians and the ecosystem. Moreover, post-conflict can be equally damaging to the environment if mass migration is reversed back to the point of origin, accompanied by resource over-exploitation necessary to rebuilt lives and revive livelihood opportunities. For example, in Afghanistan, the Middle East, and Northern Africa, coping strategies after livelihoods disruption due to war have led to widespread liquidation of the nation's natural resources such as forest cover loss, soil erosion, and water scarcity (United Nations Environment Programme 2009).

Therefore, in the reconstruction process, the environmental drivers and impacts of conflict must be managed. The fundamental needs such as health and livelihood are facilitated, and natural resources are used sustainably and distributed fairly to achieve stability and peace in the longer-term. Undoubtedly, there will be no durable peace if ecosystem services that sustain livelihood are damaged, degraded, or destroyed. In addition to ending violence and persecution, failure to address resource management mechanisms will eventually result in conflict relapse.

The approach used in this study can help fill in the data gaps resulting from the restriction in conducting field research in conflict zones. It is important to note that this methodology should only be used to complement field-based research and not to replace them. The availability of ground-truth LULCC and precise environmental data would further improve the accuracy of the model. The use of mixed-method approach of quantitative GIS technology and qualitative filed-collected personal narratives also might improve the results. Nevertheless, in the absence of field data, this approach could be used across many domains and useful for producing granular data on environmental impacts. Future work may attempt to incorporate participatory approach using interviews with displace persons to validate findings and provide a full sicario of the impact of armed conflicts.

\section{Conclusion}

Rakhine's conflict is the greatest challenge faced by the military government (Tatmadaw) in recent decades and the civilian government since they took office in 2015. Concurrently, there are growing environmental challenges such as intense deforestation, land degradation, water quality deterioration, and climate change, biodiversity loss, and depletion of inland and coastal fisheries. Land cover and land use in the country is changing rapidly and experiencing irreversible changes. Acute environmental health issues are on the rise, and ecosystem services are under an increased threat. On the other hand, natural resources and ecosystem services play a vital role in the national economy, but they are also critical to reduce Myanmar's vulnerability to climate change and natural disasters, poverty eradication, livelihood support, and peacebuilding. As mentioned above, Myanmar's long-lasting subnational conflicts are often entwined with and fueled in part by abundant natural resources. While the conflict in Rakhine is not driven solely by economic interest, the abundant natural resource wealth and geostrategic location can be a significant factor. Although the key proximate causes of increased environmental pressure in Myanmar have been documented as large-scale development projects and shifting cultivation, the underlying drivers are deeply embedded within the country's socio-economic and political context. Land alteration during and after civil war are also recognized as the crucial drivers of environmental disasters, albeit they are still poorly understood phenomena in Myanmar. A critical analysis of armed conflict's environmental impacts provides vital information on ecosystem damage triggered by conflicts and the mitigation strategies.

Our study examines the spatial and temporal pattern of environmental changes and the complex dynamics of land-cover-land-use shifts in war-torn Rakhine. By commissioning very-high-resolution-satellite-imageries and machine learning techniques, I set out to evaluate the capacity of very-highresolution-satellite data to quantify the magnitude of damage in conflict zones where the study context is notoriously difficult to assess. Remote sensing allowed for a comprehensive analysis of forest and land cover conversion in the Rohingya conflict zone in a 28590.724 ha study area in the Rakhine State of Myanmar from 2012 to 2019. Analysis reveals that the environment and ecosystem have undergone unprecedented change and have witnessed a dramatic forest cover decline. The region experienced a horrendous loss of residential area (nearly $100 \%$ wiped-out) regarding human life and livelihood loss. LULCC included an appalling expansion of burned areas and a barren and scrubland, resulting in a drastic reduction in all other forms of land cover, forest, wetland, human settlement, development, and agricultural lands. Forests predominantly covered the land, wetland ecosystems, planted/cultivated land before the conflict. However, all these land cover classes dropped off to virtually nil during the conflict, indicating a linear relationship between the environmental and human crisis and the conflict. 
It can be concluded that over the eight-year study period, the environmental degradations and lost human lives, as well as livelihood distractions, are all devastatingly high, suggesting that the impact of the conflict is intense in Rakhine, given that all changes are related to burned areas. These results from Myanmar offer useful insights for other countries with ongoing armed conflicts and civil war. The onset of armed conflicts presents a significant risk to human lives, health, and livelihood; the environment becomes a silent casualty of conflict. Although the direct environmental impacts generated by chemicals and debris can be visible and well understood, the impacts on ecosystem services are difficult to determine. However, the disruption of critical natural assets and ecosystem services is equally important for reestablishing the community as they provide basic shelter, food and protection, and economic opportunities. Hence, these environmental impacts of wartime can be extremely persistent and widespread. The results from this research pinpoint that the environment and natural resources can be adversely affected throughout the conflict cycle, contributing and to the outbreak, being degraded by the violence, and undermining post-conflict reconstruction.

This research also provides a methodological framework for future studies investigating the impacts of armed-conflicts using spatially and temporally explicit and quantifiable methods through the integration of very-high-resolution satellite data, machine learning, and regional knowledge. Although costly, the mapping approach and the use of very high-resolution satellite data were relatively robust and provided very high accuracy and outcomes over a large geographic region without integrating multi-sensor data. The study also directs further attention to examining the severity of war's impact on the environment and overall human system. The end of hostilities in conflict zones might provide access to the study sites and an opportunity to corroborate findings with field data and further investigate underlying causes of the environmental crisis and further validate findings from the satellite data in the future.

\section{Declarations}

Acknowledgment

Images provided courtesy Airbus Defense \& Space via the Harvard University Imagery Grant Program, coordinated through the Center for Geographic Analysis, Harvard University.

Author Statement

Thiri Shwesin Aung: Conceptualization, Methodology, Software, Data Curation, Formal analysis, Validation, Resources, Writing-Original draft, Visualization, Investigation.

\section{References}

AIRBUS. 2020. “GeoStore Ordering." Defence and Space 1. Retrieved August 13, 2020 (https://www.intelligence-airbusds.com/en/4871-geostoreordering).

De Alban, Jose Don T., Johanness Jamaludin, Donovan Wong De Wen, Maung Maung Than, and Edward L. Webb. 2020. “Improved Estimates of Mangrove Cover and Change Reveal Catastrophic Deforestation in Myanmar." Environmental Research Letters 15(3):34034.

De Alban, Jose Don T., Graham W. Prescott, Kevin M. Woods, Johanness Jamaludin, Kyaw Thinn Latt, Cheng Ling Lim, Aye Chan Maung, and Edward L. Webb. 2019. "Integrating Analytical Frameworks to Investigate Land-Cover Regime Shifts in Dynamic Landscapes." Sustainability (Switzerland) 11(4).

Aung, Thiri Shwesin, Thomas B. Fischer, and John Buchanan. 2020. "Land Use and Land Cover Changes along the China-Myanmar Oil and Gas Pipelines - Monitoring Infrastructure Development in Remote Conflict-Prone Regions." PLoS ONE 15(8 August):1-23.

Baral, Nabin, Joel T. Heinen, and Nabin Barai. 2019. “Linked References Are Available on JSTOR for This Article: The Maoist People 's War and Conservation in Nepal Civil Unrest, Especially Civil War in Developing." 24(1):2-11.

Baskett, John Patrick. 2016. “Myanmar Oil Palm Plantations.” Faun \& Flora International (January):1-84.

Belgiu, Mariana, and Lucian Dra. 2016. "ISPRS Journal of Photogrammetry and Remote Sensing Random Forest in Remote Sensing: A Review of Applications and Future Directions ` Gut.” 114:24-26.

Berhane, Tedros M., Charles R. Lane, Qiusheng Wu, Bradley C. Autrey, Oleg A. Anenkhonov, Victor V. Chepinoga, and Hongxing Liu. 2018. “DecisionTree, Rule-Based, and Random Forest Classification of High-Resolution Multispectral Imagery for Wetland Mapping and Inventory." Remote Sensing 10(4).

Bhagwat, Tejas, Andrea Hess, Ned Horning, Thiri Khaing, Zaw Min Thein, Moe Aung, Kyaw Htet Aung, Paing Phyo, Ye Lin Tun, Aung Htat Oo, Anthony Neil, Win Myo Thu, Melissa Songer, Katherine Lajeunesse Connette, Asja Bernd, Qiongyu Huang, Grant Connette, and Peter Leimgruber. 2017. “Losing a Jewel - Rapid Declines in Myanmar's Intact Forests from 2002-2014." 1-22. 
Bricher, Phillippa K., Arko Lucieer, Justine Shaw, Aleks Terauds, and Dana M. Bergstrom. 2013. “Mapping Sub-Antarctic Cushion Plants Using Random Forests to Combine Very High Resolution Satellite Imagery and Terrain Modelling." PLoS ONE 8(8):1-15.

Burgess, Robin, Edward Miguel, and Charlotte Stanton. 2015. “War and Deforestation in Sierra Leone.” Environmental Research Letters $10(9): 95014$.

Butsic, Van, Matthias Baumann, Anja Shortland, Sarah Walker, and Tobias Kuemmerle. 2015. "Conservation and Conflict in the Democratic Republic of Congo: The Impacts of Warfare, Mining, and Protected Areas on Deforestation." Biological Conservation 191:266-73.

Cheung, Felix, Amanda Kube, Louis Tay, Edward Diener, Joshua J. Jackson, Richard E. Lucas, Michael Y. Ni, and Gabriel M. Leung. 2020. “The Impact of the Syrian Conflict on Population Well-Being." Nature Communications 11(1).

Christophersen, Mona, and Svein Erik Stave. 2018. Advancing Sustainable Development between Conflict and Peace in Myanmar.

Clerici, N., D. Armenteras, P. Kareiva, R. Botero, J. P. Ramírez-Delgado, G. Forero-Medina, J. Ochoa, C. Pedraza, L. Schneider, C. Lora, C. Gómez, M. Linares, C. Hirashiki, and D. Biggs. 2020. “Deforestation in Colombian Protected Areas Increased during Post-Conflict Periods.” Scientific Reports 10(1):1-10.

Clodfelter, Micheal,. 2002. Warfare and Armed Conflicts:A Statistical Reference to Casualty and Other Figures, 1500-2000/. 2nd ed. Jefferson, N.C.:

Connette, Grant, Patrick Oswald, Melissa Songer, and Peter Leimgruber. 2016. "Mapping Distinct Forest Types Improves Overall Forest Identification Based on Multi-Spectral Landsat Imagery for Myanmar'S Tanintharyi Region." Remote Sensing 8(11).

Cutler, D. Richard, Thomas C. Edwards, Karen H. Beard, Adele Cutler, Kyle T. Hess, Jacob Gibson, and Joshua J. Lawler. 2007. “Random Forests for Classification in Ecology." Ecology 88(11):2783-92.

Daskin, Joshua H., and Robert M. Pringle. 2018. “Warfare and Wildlife Declines in Africa's Protected Areas.” Nature 553(7688):328-32.

Davis, John H. 1965. "The Forests of Burma." Bulletin of the Torrey Botanical Club 92(2):144.

Draulans, Dirk and Ellen Van Krunkelsven. 2002. "The Impact of War on Forest Areas in the Democratic Republic of Congo." Oryx 36(1):17.

Eniang, Edem A., Amleset Haile, and Teshale Yihdego. 2007. "Eritrean-Ethiopian War Impacts of Landmines on the Environment and Biodiversity." Environmental Policy and Law 37(6):501.

Gorelick, Noel, Matt Hancher, Mike Dixon, Simon Ilyushchenko, David Thau, and Rebecca Moore. 2017. “Google Earth Engine: Planetary-Scale Geospatial Analysis for Everyone." Remote Sensing of Environment 202:18-27.

Gorsevski, Virginia, Eric Kasischke, Jan Dempewolf, Tatiana Loboda, and Falk Grossmann. 2012. "Remote Sensing of Environment Analysis of the Impacts of Armed Con Fl Ict on the Eastern Afromontane Forest Region on the South Sudan - Uganda Border Using Multitemporal Landsat Imagery." Remote Sensing of Environment 118:10-20.

Hanson, Thor. 2018. “Biodiversity Conservation and Armed Conflict: A Warfare Ecology Perspective." Annals of the New York Academy of Sciences 1429(1):50-65.

Hanson, Thor, Thomas M. Brooks, Gustavo A. B. Da Fonseca, Michael Hoffmann, John F. Lamoreux, Gary MacHlis, Cristina G. Mittermeier, Russell A. Mittermeier, and John D. Pilgrim. 2009. "Warfare in Biodiversity Hotspots." Conservation Biology 23(3):578-87.

HRW. 2017. "Burma: Satellite Imagery Shows Mass Destruction | Human Rights Watch." Human Rights Watch. Retrieved August 9, 2020 (https://www.hrw.org/news/2017/09/19/burma-satellite-imagery-shows-mass-destruction).

HRW. 2020. “Myanmar: Imagery Shows 200 Buildings Burned | Human Rights Watch.” Human Rights Watch Report. Retrieved August 9 , 2020 (https://www.hrw.org/news/2020/05/26/myanmar-imagery-shows-200-buildings-burned).

Human Rights Watch. 2017. “Burma: 40 Rohingya Villages Burned Since October.” (November).

International Crisis Group. 2019. "A Sustainable Policy for Rohingya Refugees in Bangladesh.” (December).

Joksimovich, V. 2000. "Militarism and Ecology: NATO Ecocide in Serbia." Mediterranean Quarterly 11(4):140-60.

Jolliffe, Kim. 2014. “Ethnic Conflict and Social Services in Myanmar's Contested Regions.” The Asia Foundation (June).

Kaimowitz, David, and Angelica Fauné. 2003. "Contras and Comandantes: Armed Movements and Forest Conservation in Nicaragua's Bosawas Biosphere Reserve." Journal of Sustainable Forestry 16(3-4):21-46. 
Kissinger, Gabrielle, Phyu Phyu San, Franz Arnold, Myat Su Mon, and Naw Ei Ei Min. 2017. Background Report for Identifying the Drivers of Deforestation and Forest Degradation in Myanmar.

Leimgruber, Peter, Daniel S. Kelly, Marc K. Steininger, Jake Brunner, Thomas Müller, and Melissa Songer. 2005. "Forest Cover Change Patterns in Myanmar (Burma) 1990-2000." Environmental Conservation 32(4):356-64.

Lim, Cheng Ling, Graham W. Prescott, Jose Don T. De Alban, Alan D. Ziegler, and Edward L. Webb. 2017. "Untangling the Proximate Causes and Underlying Drivers of Deforestation and Forest Degradation in Myanmar." Conservation Biology 31(6):1362-72.

Machlis, Gary E., and Thor Hanson. 2011. "Warfare Ecology.” NATO Science for Peace and Security Series C: Environmental Security 113(8):33-40.

Madden, Marguerite, and Amy Ross. 2009. “Genocide and GIScience: Integrating Personal Narratives and Geographic Information Science to Study Human Rights." Professional Geographer 61(4):508-26.

Mellor, Andrew, Andrew Haywood, Christine Stone, and Simon Jones. 2013. "The Performance of Random Forests in an Operational Setting for Large Area Sclerophyll Forest Classification." Remote Sensing 5(6):2838-56.

Myanmar Information Management Unit. 2020. Overview of the February 2020 3W RAKHINE State.

Nackoney, Janet, Giuseppe Molinario, Peter Potapov, Svetlana Turubanova, Matthew C. Hansen, and Takeshi Furuichi. 2014. “Impacts of Civil Conflict on Primary Forest Habitat in Northern Democratic Republic of the Congo, 1990-2010." Biological Conservation 170:321-28.

Naseh, Mitra, Miriam Potocky, Paul H. Stuart, and Sara Pezeshk. 2018. "Repatriation of Afghan Refugees from Iran: A Shelter Profile Study." Journal of International Humanitarian Action 3(1).

Noi Phan, Thanh, Verena Kuch, and Lukas W. Lehnert. 2020. “Land Cover Classification Using Google Earth Engine and Random Forest Classifier-the Role of Image Composition." Remote Sensing 12(15).

Nomura, Keiko, and Edward T. A. Mitchard. 2018. “More than Meets the Eye: Using Sentinel-2 to Map Small Plantations in Complex Forest Landscapes." Remote Sensing 10(11).

Nomura, Keiko, Edward T. A. Mitchard, Genevieve Patenaude, Joan Bastide, Patrick Oswald, and Thazin Nwe. 2019. "Oil Palm Concessions in Southern Myanmar Consist Mostly of Unconverted Forest." Scientific Reports 9(1):1-9.

OCHA. 2015. "Rakhine State, Myanmar - Land Cover Analysis, 2015 - Myanmar." Myanmar 1. Retrieved August 13, 2020

(https://reliefweb.int/map/myanmar/rakhine-state-myanmar-land-cover-analysis-2015).

Olofsson, Pontus, Giles M. Foody, Martin Herold, Stephen V. Stehman, Curtis E. Woodcock, and Michael A. Wulder. 2014. “Good Practices for Estimating Area and Assessing Accuracy of Land Change." Remote Sensing of Environment 148:42-57.

Prescott, Graham W., William J. Sutherland, Daniel Aguirre, Matthew Baird, Vicky Bowman, Jake Brunner, Grant M. Connette, Martin Cosier, David Dapice, Jose Don T. De Alban, Alex Diment, Julia Fogerite, Jefferson Fox, Win Hlaing, Saw Htun, Jack Hurd, Katherine LaJeunesse Connette, Felicia Lasmana, Cheng Ling Lim, Antony Lynam, Aye Chan Maung, Benjamin McCarron, John F. McCarthy, William J. McShea, Frank Momberg, Myat Su Mon, Than Myint, Robert Oberndorf, Thaung Naing Oo, Jacob Phelps, Madhu Rao, Dietrich Schmidt-Vogt, Hugh Speechly, Oliver Springate-Baginski, Robert Steinmetz, Kirk Talbott, Maung Maung Than, Tint Lwin Thaung, Salai Cung Lian Thawng, Kyaw Min Thein, Shwe Thein, Robert Tizard, Tony Whitten, Guy Williams, Trevor Wilson, Kevin Woods, Alan D. Ziegler, Michal Zrust, and Edward L. Webb. 2017. "Political Transition and Emergent ForestConservation Issues in Myanmar." Conservation Biology 31(6):1257-70.

Reardon, Sara. 2018. "FARC and the Forest: Peace Is Destroying Colombia's Jungle - and Opening It to Science." Nature 558(7709):169-70.

Richards, Daniel R., and Daniel A. Friess. 2016. "Rates and Drivers of Mangrove Deforestation in Southeast Asia, 2000-2012." Proceedings of the National Academy of Sciences of the United States of America 113(2):344-49.

Rustad, Siri Camilla Aas, Jan Ketil Rød, Wenche Larsen, and Nils Petter Gleditsch. 2008. "Foliage and Fighting: Forest Resources and the Onset, Duration, and Location of Civil War." Political Geography 27(7):761-82.

Selth, Andrew. 2018. Myanmar's Armed Forces and the Rohingya Crisis.

Sesnie, Steven E., Bryan Finegan, Paul E. Gessler, ALISTAIR M. S. Smith, Ramos Bendana Zayra, and Sirpa Thessler. 2010. "The Multispectral Separability of Costa Rican Rainforest Types with Support Vector Machines and Random Forest Decision Trees." International Journal of Remote Sensing 31(11):2885-2909.

Sharma, Ram C., Keitarou Hara, and Hidetake Hirayama. 2017. "A Machine Learning and Cross-Validation Approach for the Discrimination of Vegetation Physiognomic Types Using Satellite Based Multispectral and Multitemporal Data.” Scientifica 2017.

Page $10 / 17$ 
Shelestov, Andrii, Mykola Lavreniuk, Nataliia Kussul, Alexei Novikov, and Sergii Skakun. 2017. “Exploring Google Earth Engine Platform for Big Data Processing: Classification of Multi-Temporal Satellite Imagery for Crop Mapping." Frontiers in Earth Science 5(February):1-10.

Sidel, Victor W., and Barry S. Levy. 2008. "The Health Impact of War." International Journal of Injury Control and Safety Promotion 15(4):189-95.

Sidhu, Nanki, Edzer Pebesma, and Gilberto Câmara. 2018. “Using Google Earth Engine to Detect Land Cover Change: Singapore as a Use Case.” European Journal of Remote Sensing 51(1):486-500.

Skakun, Sergii, Christopher O. Justice, Nataliia Kussul, Andrii Shelestov, and Mykola Lavreniuk. 2019. "Satellite Data Reveal Cropland Losses in SouthEastern Ukraine Under Military Conflict." Frontiers in Earth Science 7(November):1-7.

Spyrou, E., B. F. Hobbs, M. D. Bazilian, and D. Chattopadhyay. 2019. "Planning Power Systems in Fragile and Conflict-Affected States." Nature Energy 4(4):300-310.

Stevens, Kara, Lindsay Campbell, Gerald Urquhart, Dan Kramer, and Jiaguo Qi. 2011. “Examining Complexities of Forest Cover Change during Armed Conflict on Nicaragua's Atlantic Coast." Biodiversity and Conservation 20(12):2597-2613.

Suarez, Andres, Paola Arias-arévalo, Eliana Martinez-mera, Juan Carlos Granobles-torres, and Tatiana Enríquez-acevedo. 2018. "Involving Victim Population in Environmentally Sustainable Strategies: An Analysis for Post-Conflict Colombia." Science of the Total Environment 643:1223-31.

UNHCR. 2012. Myanmar Report.

United Nations Environment Programme. 2009. From Conflict to Peacebuilding.

Wang, Chuyuan, and Soe W. Myint. 2016. “Environmental Concerns of Deforestation in Myanmar 2001-2010.” Remote Sensing 8(9):1-15.

Weir, Doug, Dan McQuillan, and Robert A. Francis. 2019. "Civilian Science: The Potential of Participatory Environmental Monitoring in Areas Affected by Armed Conflicts." Environmental Monitoring and Assessment 191(10).

Witmer, Frank D. W. 2008. "Detecting War-Induced Abandoned Agricultural Land in Northeast Bosnia Using Multispectral, Multitemporal Landsat TM Imagery." International Journal of Remote Sensing 29(13):3805-31.

Witmer, Frank D. W. 2015. “Remote Sensing of Violent Conflict: Eyes from Above." International Journal of Remote Sensing 36(9):2326-52.

Witmer, Frank D. W., and John O'Loughlin. 2009. "Satellite Data Methods and Application in the Evaluation of War Outcomes: Abandoned Agricultural Land in Bosnia-Herzegovina after the 1992-1995 Conflict." Annals of the Association of American Geographers 99(5):1033-44.

Woods, Kevin. 2015. "Forest Trade and Finance March 2015 Commercial Agriculture Expansion in Myanmar: Links to Deforestation , Conversion Timber , EXECUTIVE SUMMARY." (March):1-51.

Woods, Kevin M. 2019. Forest Policy Trade and Finance Initiative Natural Resource Governance Reform and the Peace Process in Myanmar. Woods, Kevin M. 2019. “Green Territoriality: Conservation as State Territorialization in a Resource Frontier." Human Ecology $217-32$.

Yang, Rongfeng, Yi Luo, Kun Yang, Liang Hong, and Xiaolu Zhou. 2019. "Analysis of Forest Deforestation and Its Driving Factors in Myanmar from 1988 to 2017." Sustainability (Switzerland) 11(11):1-15.

Zúñiga-upegui, P., C. Arnaiz-schmitz, C. Herrero-jáuregui, and S. M. Smart. 2019. "Exploring Social-Ecological Systems in the Transition from War to Peace: A Scenario-Based Approach to Forecasting the Post-Con Fl Ict Landscape in a Colombian Region." Science of the Total Environment 695:133874.

\section{Figures}




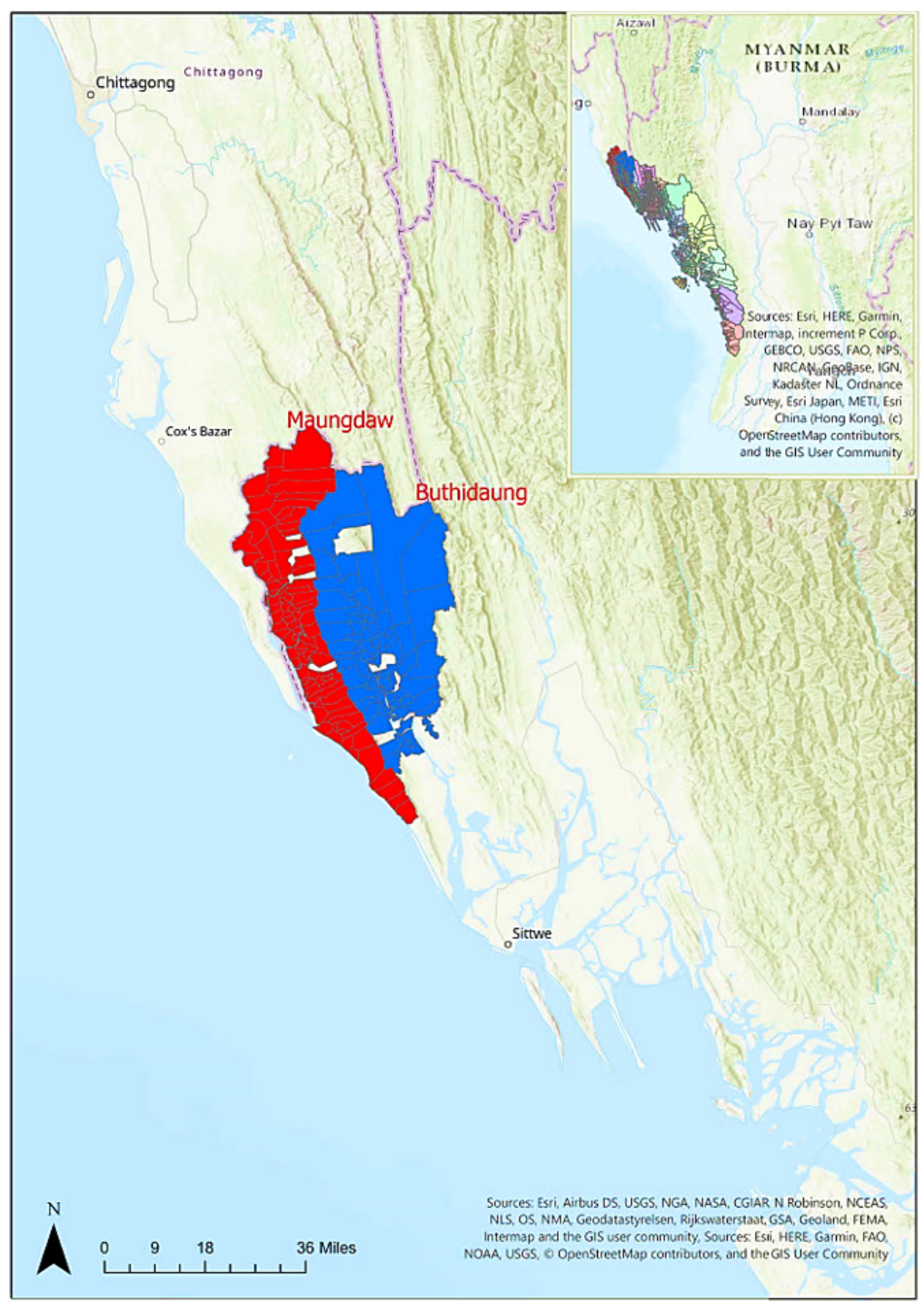

Figure 1

Study area map. Note: The designations employed and the presentation of the material on this map do not imply the expression of any opinion whatsoever on the part of Research Square concerning the legal status of any country, territory, city or area or of its authorities, or concerning the delimitation of its frontiers or boundaries. This map has been provided by the authors. 


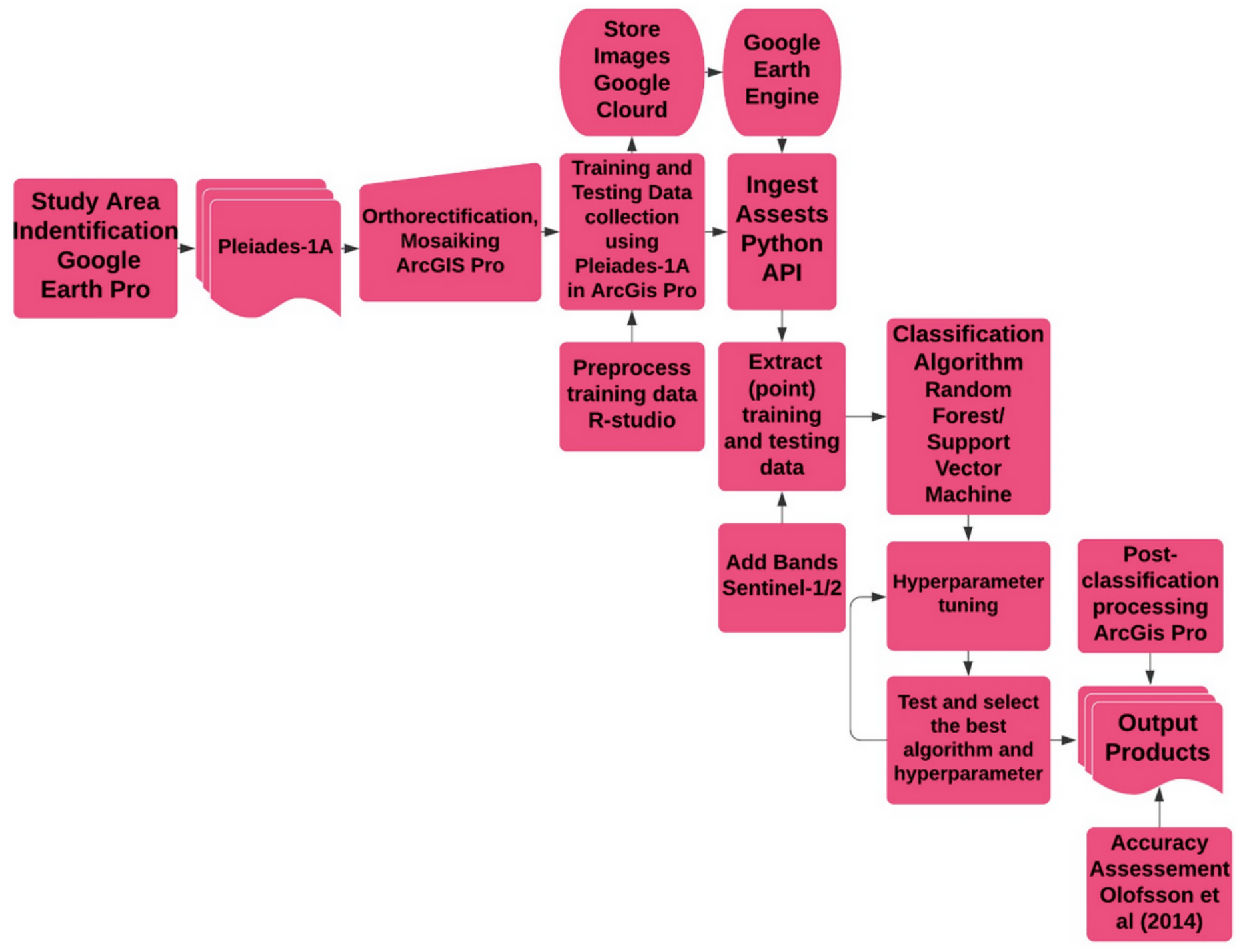

Figure 2

Workflow for classifying environmental changes in the conflict zone in Rakhine 


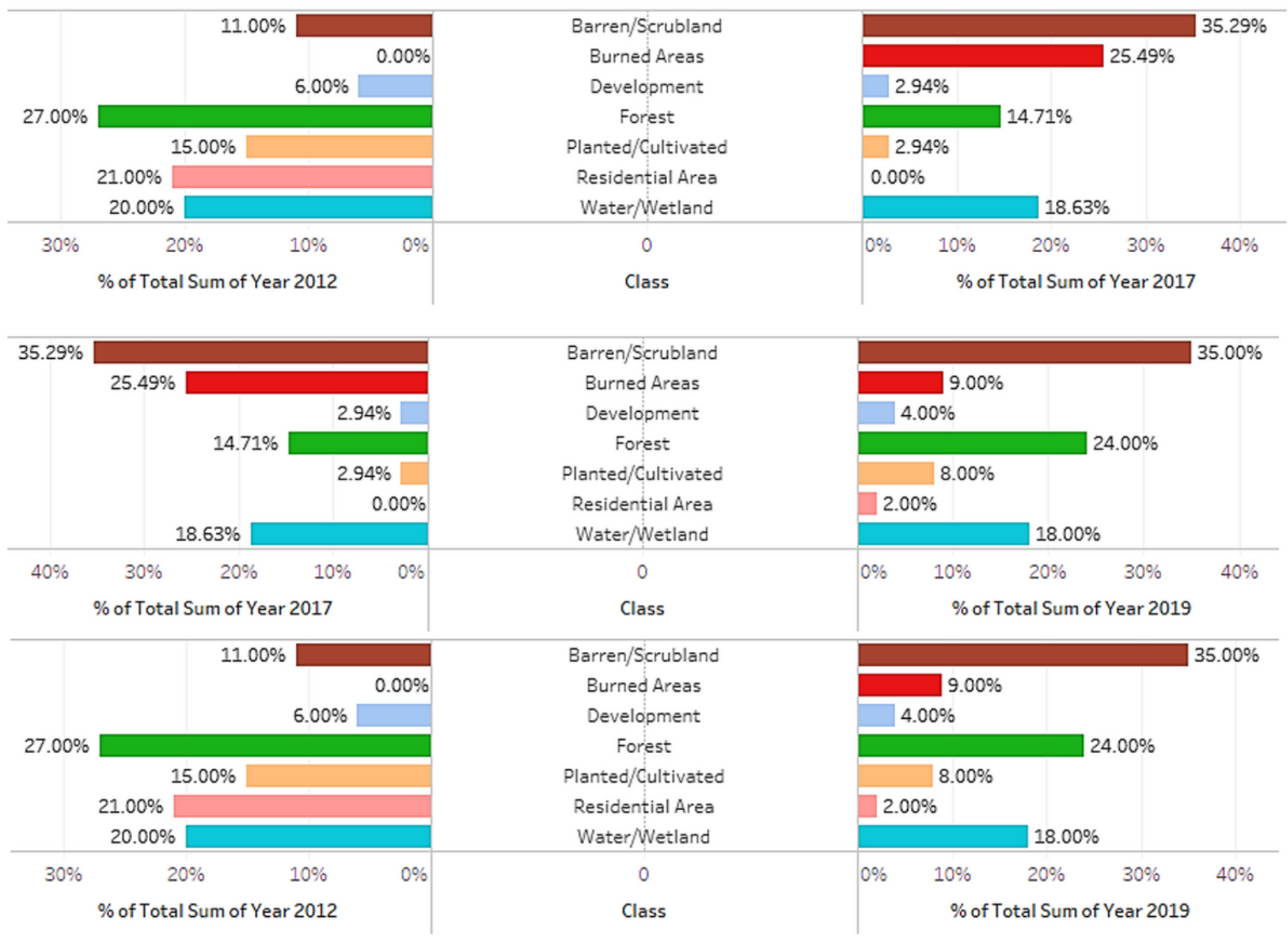

\section{Figure 3}

Area change in land cover land use classes for three study periods 


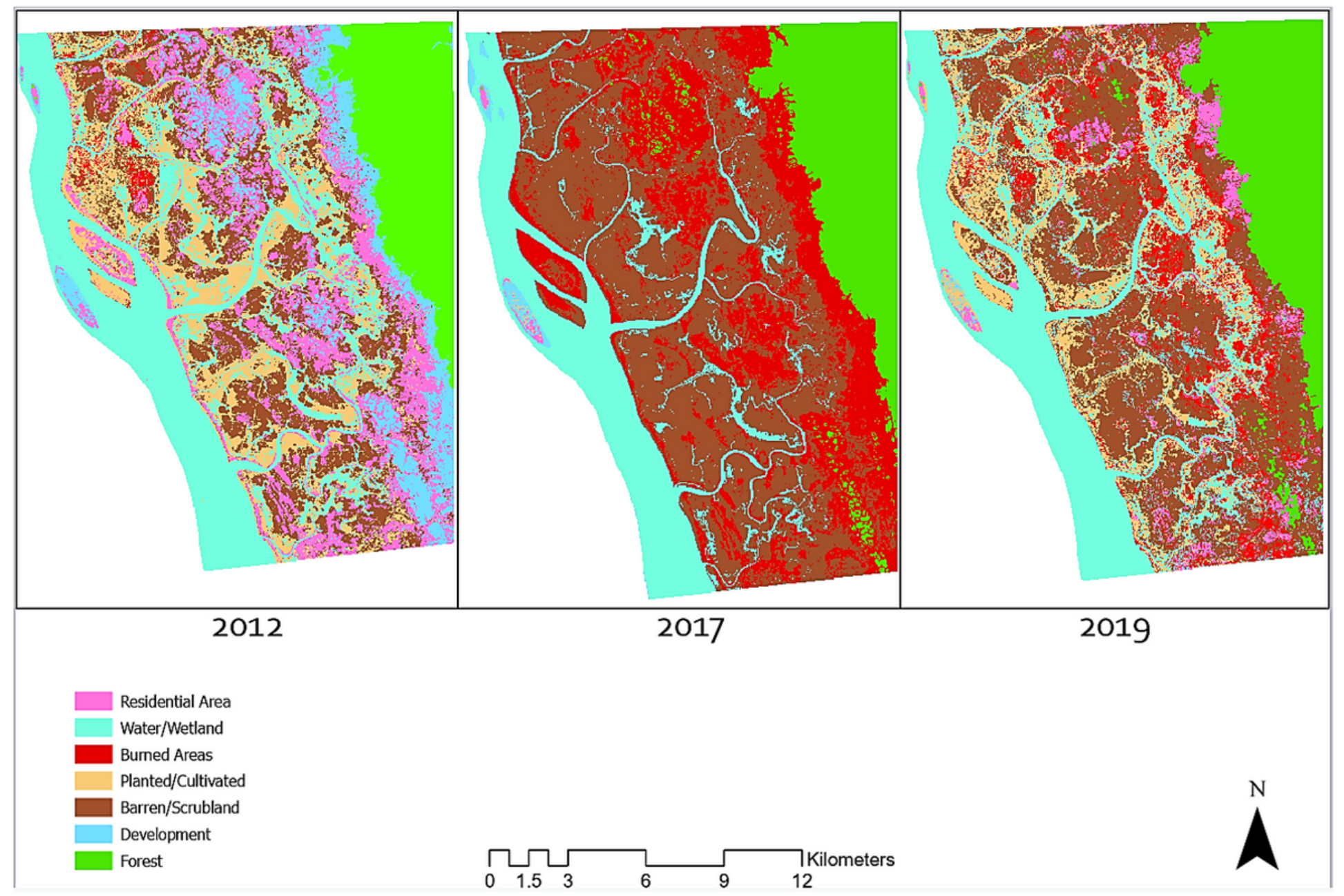

Figure 4

2012 Pre-conflict, 2017during-conflict and 2019 Post-conflict land cover map for the study area classified into five major land cover classes, including residential arear (pink), water/wetland (aqua), burned area (red), planted/cultivated (beige), barren/ scrubland (brown), development (blue), forest (green). Note: The designations employed and the presentation of the material on this map do not imply the expression of any opinion whatsoever on the part of Research Square concerning the legal status of any country, territory, city or area or of its authorities, or concerning the delimitation of its frontiers or boundaries. This map has been provided by the authors. 


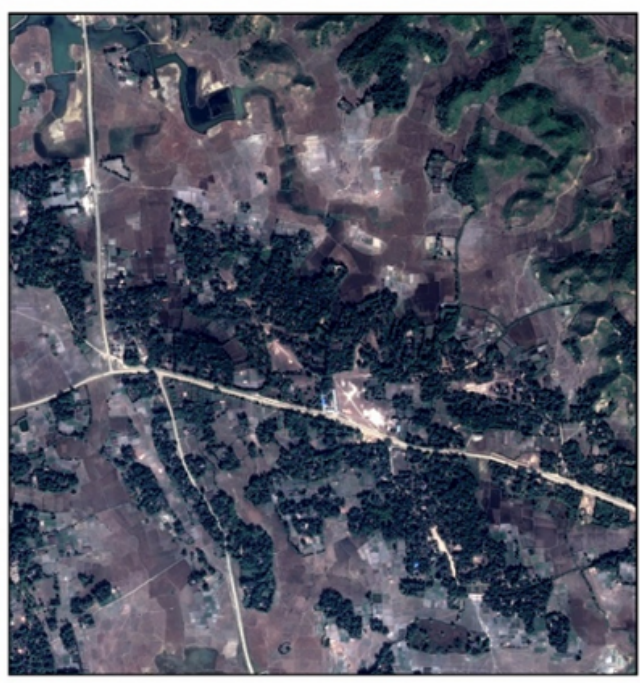

$2012(A)$

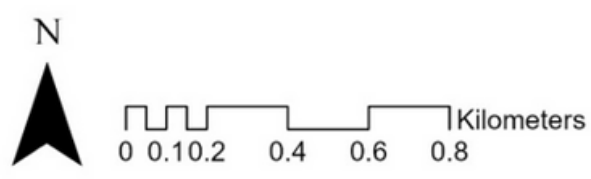

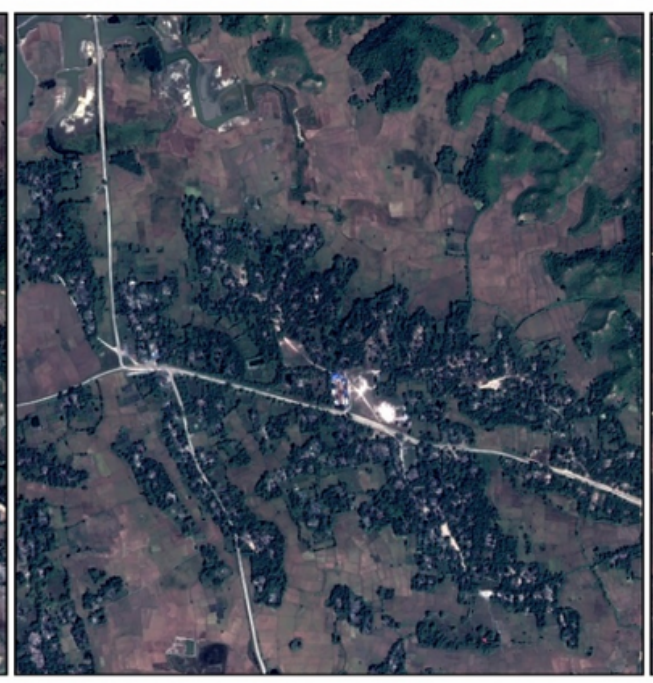

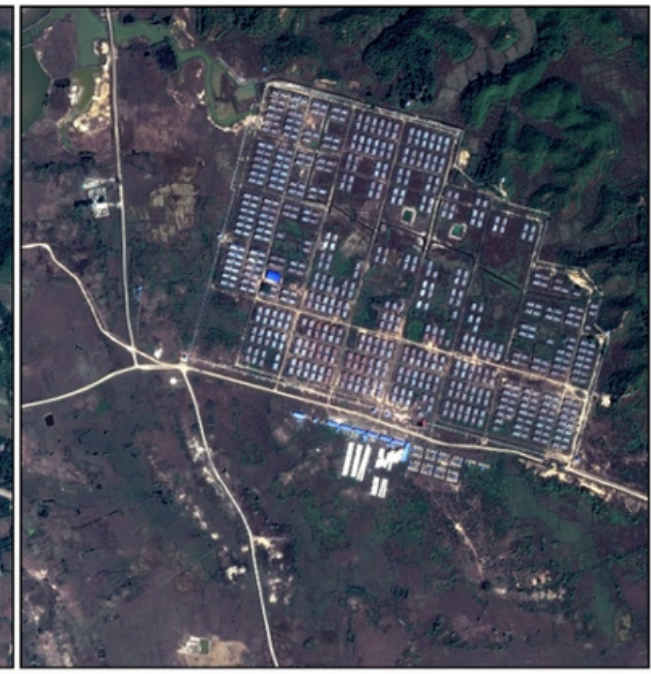

2017 (B)

(D)

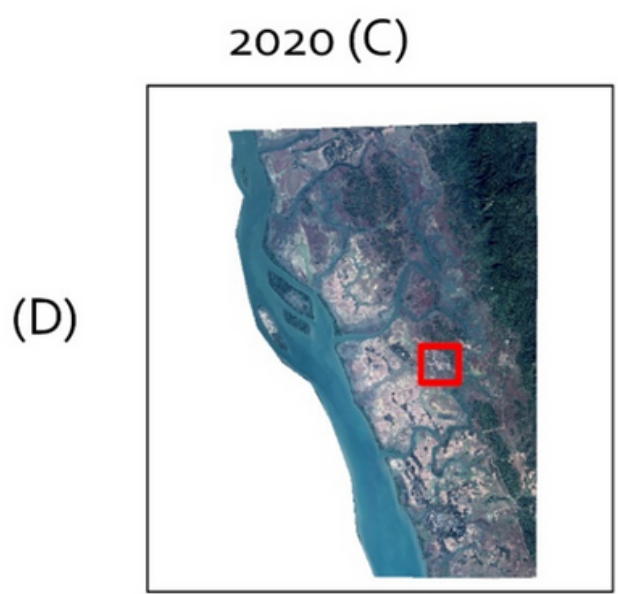

\section{Figure 5}

True color composite map of the study area pre-, during- and post-conflict in Rakhine, Myanmar. Image A is from November 17, 2012, showing the area before the conflict. Image B is from October 28, 2012, showing the area during the conflict. Image C is from showing the area from November 26,2019 after the conflict. Image D shows the location of the images in ROI. Source: https://www.intelligence-airbusds.com/geostore/. (Order number: S0200254-2-01) Note: The designations employed and the presentation of the material on this map do not imply the expression of any opinion whatsoever on the part of Research Square concerning the legal status of any country, territory, city or area or of its authorities, or concerning the delimitation of its frontiers or boundaries. This map has been provided by the authors. 


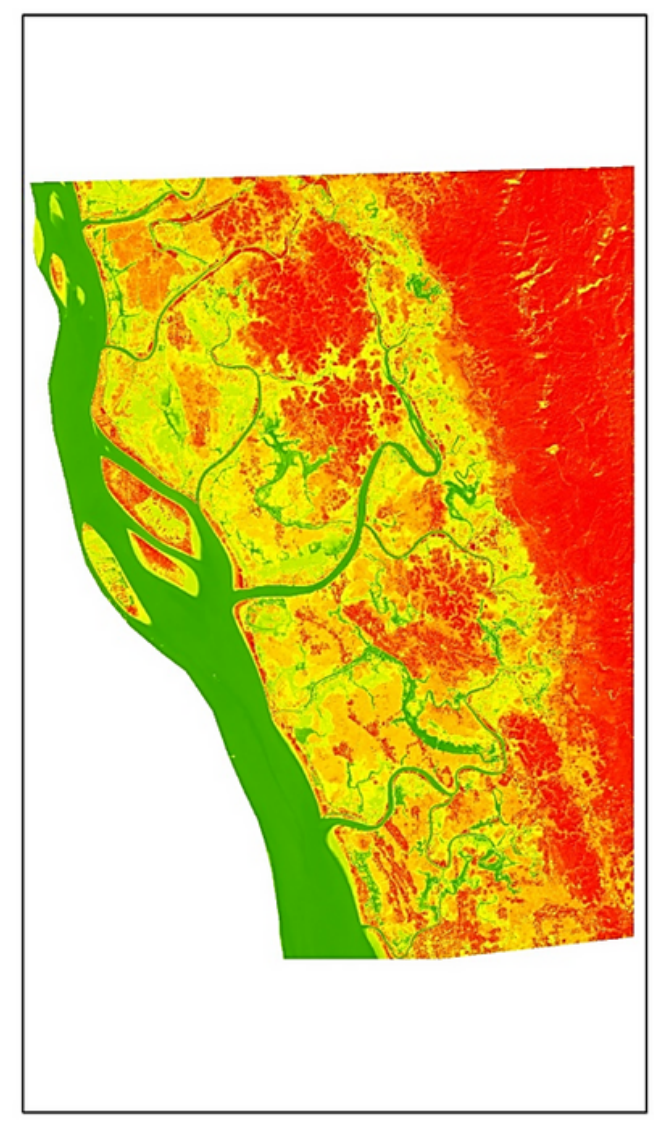

$2012(\mathrm{~A})$

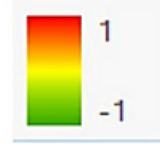

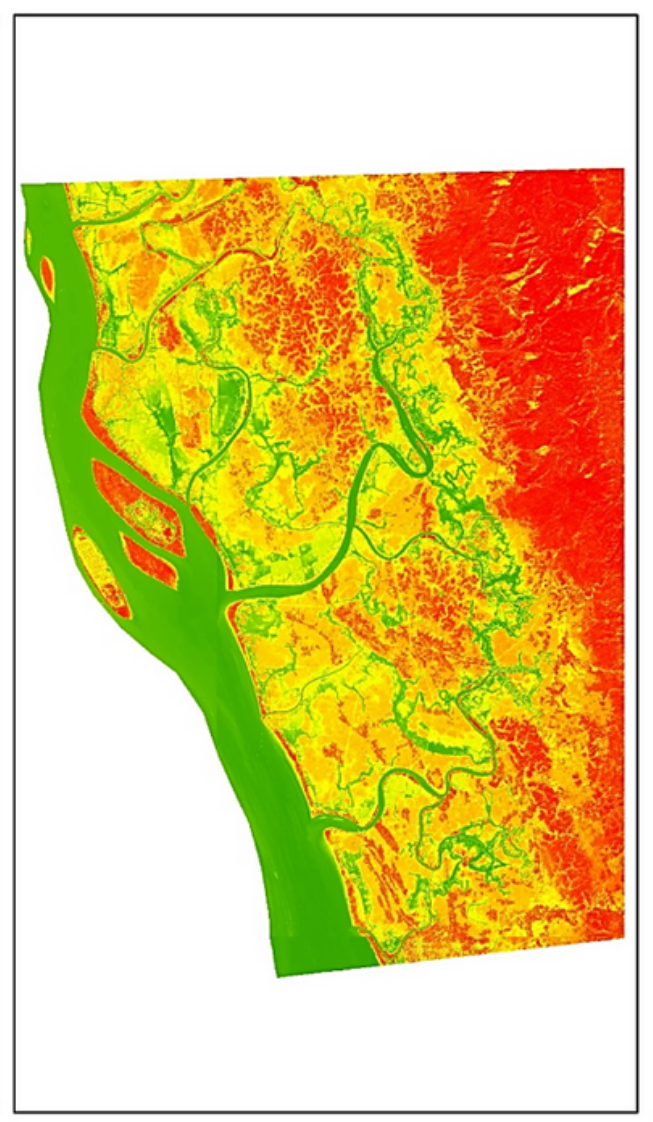

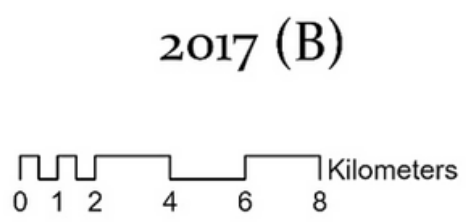

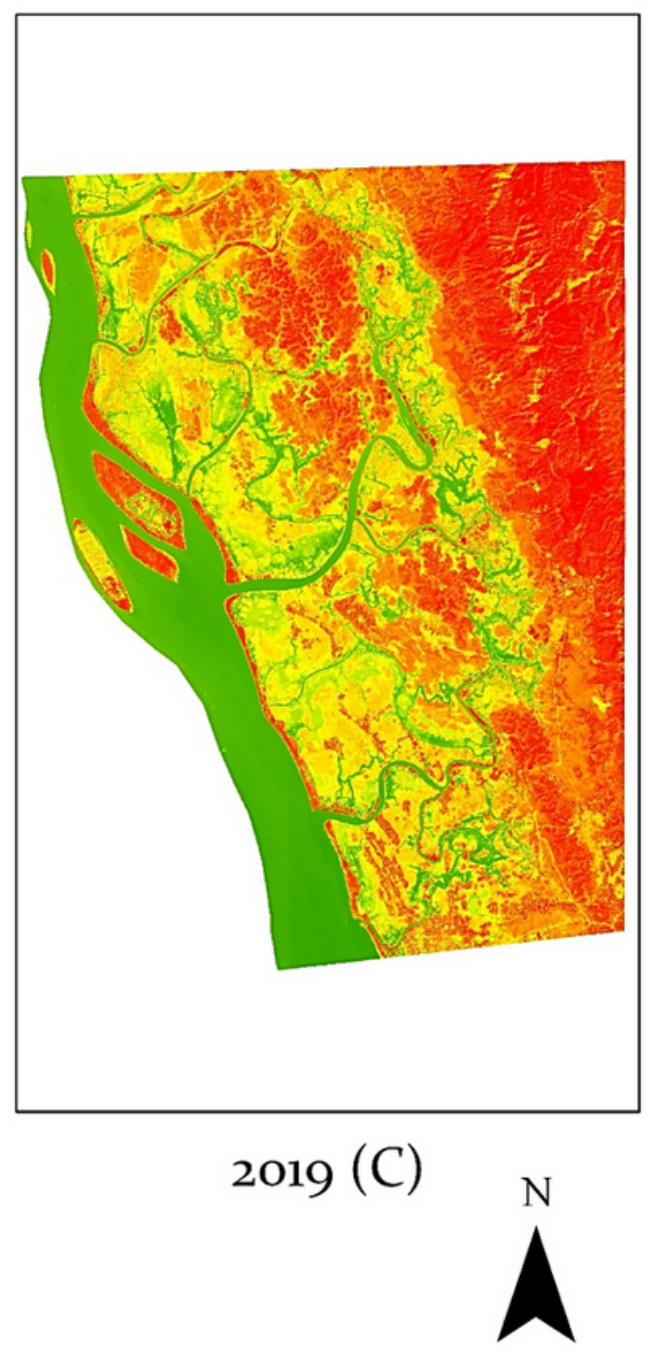

Figure 6

NDVI in the study region for the three periods. The colors represent values ranging between +1 to -1 . Higher NDVI values indicate greener and healthier vegetation, while lower values represent stressed and depleted vegetation or barren land. Note: The designations employed and the presentation of the material on this map do not imply the expression of any opinion whatsoever on the part of Research Square concerning the legal status of any country, territory, city or area or of its authorities, or concerning the delimitation of its frontiers or boundaries. This map has been provided by the authors.

\section{Supplementary Files}

This is a list of supplementary files associated with this preprint. Click to download.

- SupplementaryMaterialRK1.docx 